\title{
1-metilciclopropeno e salicilato de metila reduzem injúrias por frio em nêspera 'Fukuhara' refrigerada
}

\author{
1-methylcyclopropene and methyl salicylate reduce chilling injury of 'Fukuhara' loquat \\ under cold storage
}

\section{Fernando Kazuhiro Edagi ${ }^{I}$ Fabiana Fumi Sasaki Ivan Sestari ${ }^{I}$ Felipe de Angelis Monteiro Terra Beatriz Giro ${ }^{I}$ Ricardo Alfredo Kluge ${ }^{I^{*}}$}

\section{RESUMO}

\begin{abstract}
Este trabalho teve como objetivo verificar o efeito da aplicação de 1-metilciclopropeno (1-MCP) e do salicilato de metila (MeSA) no controle de injúrias pelo frio em nêsperas 'Fukuhara'. Quatro concentrações de 1-MCP foram aplicadas (0, 50, 500 e 5000nL $\left.L^{-1}\right)$, além do MeSA $(0,01 \mathrm{mM})$, associado ou não ao 1-MCP 500nL $L^{-1}$. Após os tratamentos os frutos foram armazenados a $1{ }^{\circ} \mathrm{C}$ durante 60 dias. As determinações realizadas foram: firmeza de polpa, índice de escurecimento $e$ podridão, acidez titulável, pH, teor de sólidos solúveis, teor de ácido ascórbico e atividade da enzima polifenoloxidase (PPO). Após 60 dias de armazenamento refrigerado, não foi observado desenvolvimento de escurecimento interno nos frutos tratados com 1-MCP e MeSA. Os frutos controle apresentaram elevados indices de escurecimento interno, juntamente com elevada atividade de PPO. Os frutos apresentaram aumento de firmeza de polpa durante o armazenamento refrigerado, independente do tratamento aplicado.
\end{abstract}

Palavras-chave: Eriobotrya japonica, escurecimento interno, conservação, armazenamento refrigerado.

\begin{abstract}
This study was carried out whit the objective to verify the effect of 1-methylcyclopropene (1-MCP) and methyl salicylate (MeSA) in chilling injury control of 'Fukuhara' loquat fruit. It was applied four concentrations of $1-\mathrm{MCP}(0,50,500$ e 5,000nL $L^{-1}$ ) and $0,01 \mathrm{mM}$ of MeSA associated or not to $500 n L L^{-1}$ of $1-M C P$. The fruit were stored at $1{ }^{\circ} \mathrm{C}$ during 60 days. The variables analyzed were flesh firmness, $\mathrm{pH}$, titratable acidity, soluble solids content, ascorbic acid content and activity of polyphenol oxidase (PPO). After 60 days of cold storage, there was no development of internal browning in fruit treated with 1-MCP and MeSA. Fruits without treatment showed higher levels of internal browning and high activity of PPO enzyme.
\end{abstract}

All treatments showed increase of flesh firmness during cold storage.

Key words: Eriobotrya japonica, internal browning, firmness, cold storage.

\section{INTRODUÇÃO}

A nespereira (Eriobotrya japonica Lindl.), da família Rosaceae, é originada da China. Este país, juntamente com a Espanha, é um dos maiores produtores mundiais de nêsperas. No Brasil, a produção concentra-se no Estado de São Paulo, na região de Mogi das Cruzes. Apesar de o país ser potencialmente um grande produtor de nêspera, a curta vida-deprateleira é um dos fatores que encarecem o preço final desse fruto, constituindo um obstáculo para o aumento da sua produção e popularização de seu consumo (CAMPOS et al., 2007).

A nêspera, um fruto não-climatérico, assim como outras frutas de clima subtropical e tropical, quando armazenada por longos períodos sob refrigeração, desenvolve desordens fisiológicas associadas ao frio. Dentre os sintomas de injúria pelo frio em nêsperas, estão o escurecimento interno da polpa, a lignificação e o aumento de firmeza (DING et al., 2002a; CAI et al., 2006a). O escurecimento interno tem causa enzimática, quando os compostos fenólicos presentes nas células do fruto são oxidados à quinonas,

'Departamento de Ciências Biológicas, Escola Superior de Agricultura "Luiz de Queiroz", Universidade de São Paulo (USP), 13418900, Piracicaba, SP, Brasil. E-mail: rakluge@esalq.usp.br. *Autor para correspondência. 
que, uma vez polimerizadas com proteínas ou aminoácidos, formam compostos de cor escura (DING et al., 1998b). A principal enzima responsável pela oxidação de compostos fenólicos é a polifenoloxidase (PPO, EC 1.10.3.1). Com relação à lignificação, é uma desordem particular de nêsperas, podendo prejudicar sua comercialização, devido ao aumento da firmeza e à perda de suculência (CAI et al., 2006a,b,c; SHAN et al., 2008; YANG et al., 2008).

A recomendação de temperatura para a conservação de nêspera tem sido 0 a $6^{\circ} \mathrm{C}$, podendo os frutos serem armazenados durante $2 \mathrm{a} 4$ semanas nessas condições, dependendo da cultivar e estádio de maturação (DING et al., 1998b; CAMPOS et al., 2007).

Para prolongar o benefício da refrigeração, técnicas complementares têm sido testadas, como forma de aumentar a resistência dos frutos a armazenamentos mais longos. Essas técnicas incluem uso de atmosfera modificada, tratamentos térmicos e uso de produtos químicos ou naturais.

Dentre os produtos que potencialmente podem trazer bons resultados, em associação com a refrigeração, estão os compostos salicilados, como o metil salicilato (MeSA), que provém da via dos metabólitos secundários. Em plantas, o MeSA participa do desenvolvimento de resistência sistêmica adquirida contra patógenos (VAN LOON \& ANTONIW, 1982). Os compostos salicilados também podem ativar sistemas antioxidantes, os quais removem espécies reativas de oxigênio sob condições de estresse oxidativo, em situações de ataque de fungos e baixas temperaturas (XU \& TIAN, 2008). Os compostos salicilados podem também bloquear a produção de etileno (VANALTVORST \& BOVY, 1995) e retardar os efeitos causados por esse hormônio. Outro composto que pode auxiliar no aumento da vida pós-colheita dos frutos controlando os efeitos do etileno é o 1metilciclopropeno (1-MCP), que se liga de forma irreversível aos sítios de ação desse hormônio vegetal, bloqueando, assim, os efeitos do etileno (BLANKENSHIP \& DOLE, 2003). Dessa forma, com a supressão da produção e da ação do etileno, é possível retardar a senescência dos frutos e adiar a formação de radicais livres, responsáveis pela saturação de ácidos graxos presentes na membrana plasmática, que causam a descompartimentalização celular, tornando as injúrias pelo frio mais severas (SALA, 1998).

Devido ao potencial de produção da nêspera e a falta de informações na literatura, principalmente no país, a respeito dos efeitos da utilização de compostos como 1-MCP e MeSA na manutenção da qualidade pós-colheita de nêsperas, este trabalho teve como objetivo verificar o efeito do
1-MCP associado ou não ao MeSA sobre a incidência de injúrias por frio em nêsperas 'Fukuhara', armazenadas em baixa temperatura, bem como em aspectos relacionados à qualidade da fruta e algumas respostas bioquímicas a estes tratamentos.

\section{MATERIAL E MÉTODOS}

Nêsperas 'Fukuhara' foram colhidas em plantação comercial localizado no município de Mogi das Cruzes, SP (23 $\left.31^{\prime} \mathrm{S}, 46^{\circ} 11^{\prime} \mathrm{W}\right)$, e transportadas para a ESALQ/USP, em Piracicaba, SP. Os frutos foram rigorosamente selecionados quanto ao tamanho, ponto de maturação (com base na cor da casca) e ausência de doenças e danos mecânicos.

Os seguintes tratamentos foram aplicados: 1-MCP (SmartFresh ${ }^{\mathrm{SM}}$ - Rohm and Haas Quimica Ltda) nas concentrações de 50,500 e $5000 \mathrm{~nL} \mathrm{~L}^{-1}$, MeSA $(0,01 \mathrm{mM}), 1-\mathrm{MCP}\left(500 \mathrm{~nL} \mathrm{~L}^{-1}\right)+\mathrm{MeSa}(0,01 \mathrm{mM})$, além do controle. Para a aplicação do 1-MCP, foram utilizadas caixas herméticas de $0,150 \mathrm{~m}^{3}$ as quais mantiveram-se fechadas durante $12 \mathrm{~h}$ a $20^{\circ} \mathrm{C}$ para a liberação do gás. A aplicação do MeSA foi por imersão durante 5 minutos. Após a aplicação dos tratamentos, os frutos foram colocados em embalagens de tereftalato de polietileno (PET) e embalados com filme de policloreto de vinila (PVC) com espessura de $14 \mu \mathrm{m}$ e armazenados a $1^{\circ} \mathrm{Ce}$ 90\% UR durante 60 dias, sendo avaliados a cada 15 dias. O delineamento experimental foi inteiramente ao acaso, em esquema fatorial 6X4 (seis tratamentos e quatro tempos de armazenamento). Foram utilizadas quatro repetições de 12 frutos por tratamento.

As seguintes variáveis foram determinadas: a) Índices de escurecimento interno e de podridão: dependendo da área da superfície afetada, os frutos foram classificados em cinco categorias: $0=0 \%, 1<5 \%$, $2=5-25 \%, 3=25-50 \%$ e $4=>50 \%$. A seguir, foram calculados os índices de podridões e de escurecimento de polpa através da fórmula preconizada por CAI et al. (2006c) : Índice $=(\Sigma$ notas x número de frutos afetados $) /$ (4 x total de frutos da amostra). Os frutos foram considerados não aptos à comercialização quando atingiram valores superiores a 0,4 de índice ou quando foram atribuídas as notas 3 ou 4 (CAI et al., 2006c);

b) Atividades da polifenoloxidase (PPO): foi utilizada a metodologia descrita por CAI et al. (2006a,c). Para extração, a polpa do fruto foi macerada em nitrogênio líquido. Em $2 \mathrm{~g}$ de polpa macerada, foram adicionados $8 \mathrm{~mL}$ de tampão fosfato de sódio $(0,1 \mathrm{M}, \mathrm{pH} 6,0)$ e centrifugados a $10000 \mathrm{xg}$, à $4^{\circ} \mathrm{C}$, durante $15 \mathrm{~min}$. Para mensurar a atividade, foi adicionado $0,5 \mathrm{~mL}$ de solução de pirocatecol $(100 \mathrm{mM})$ a $1,5 \mathrm{~mL}$ de extrato e $1,0 \mathrm{~mL}$ de tampão fosfato de sódio. Foram aguardados 2 min à 
$25^{\circ} \mathrm{C}$ para execução da leitura. As leituras foram realizadas em espectrofotômetro a $410 \mathrm{~nm}$. A atividade foi expressa em unidades (U) $\mathrm{g}^{-1}$ polpa, sendo $1 \mathrm{U}$ correspondente ao aumento de 0,01 na absorbância por minuto;

c) Firmeza de polpa: utilizando-se penetrômetro digital com ponteira plana e $5 \mathrm{~mm}$ de diâmetro, foram efetuadas duas leituras por fruto, em lados opostos da região equatorial deles, após uma pequena e superficial remoção da casca. Os resultados foram expressos em Newtons;

d) Teor de sólidos solúveis (SS), acidez titulável (AT) e teor de ácido ascórbico (AA): o teor de SS foi determinado em refratômetro digital (Atago) com os resultados expressos em ${ }^{\circ}$ Brix. Para a determinação da AT, $10 \mathrm{~g}$ da amostra triturada foi colocada em $90 \mathrm{~mL} \mathrm{de}$ água destilada. Foi efetuada titulação potenciométrica com $\mathrm{NaOH} 0,1 \mathrm{~N}$ até $\mathrm{pH} 8,10$ e os resultados foram expressos em \%. O teor de AA foi determinado por titulação, através da redução do 2,6-diclorofenol indolfenol-sódio (DCFI) pelo ácido ascórbico. Foram pesadas $10 \mathrm{~g}$ da amostra e colocadas em Erlenmeyer contendo 50mL de solução de ácido oxálico. A titulação foi efetuada com DCFI até atingir a coloração rosada persistente por 15 segundos. Os resultados foram expressos em mg de ácido ascórbico por $100 \mathrm{~g}$ de polpa.

Os resultados obtidos foram submetidos à análise de variância e a diferença mínima significativa foi calculada $(\mathrm{P} \leq 0,05)$. Diferenças entre dois tratamentos maiores que a soma de dois erros padrões foram consideradas significativas.

\section{RESULTADOS E DISCUSSÃO}

As aplicações de 1-MCP e MeSA, isolados ou em associação, foram eficientes no controle do escurecimento interno da polpa dos frutos, foram observados índices de escurecimento inferiores a 0,4 durante o armazenamento (Figura 1A). Por outro lado, os frutos do controle apresentaram índice de escurecimento acima de 0,4 a partir de 45 dias de armazenamento.

O escurecimento da polpa é um dos sintomas de injúria por frio em nêsperas, causado pela oxidação dos compostos fenólicos (DING et al., 1998a). Segundo CAI et al. (2006c), o escurecimento da polpa ocorre devido ao aumento da permeabilidade das membranas celulares devido à senescência. A diminuição do escurecimento de polpa causada pelo 1-MCP e pelo MeSA pode estar relacionada com o retardo na senescência dos frutos. O estágio de senescência é caracterizado, entre outros, pela formação de radicais livres, os quais podem danificar as membranas celulares. O 1-MCP, ao bloquear a ação do etileno, retarda a senescência, enquanto que o MeSA, além de diminuir a produção de etileno atua diretamente como antioxidante, aliviando os efeitos do estresse oxidativo, enquanto os frutos estão expostos à baixa temperatura (ZHANG et al., 2003). CAI et al. (2006c) também observaram redução do escurecimento da polpa em nêsperas cv. 'Luoyangqing', tratados com 1-MCP em comparação com frutos sem tratamento ou com aplicação de etileno.

Frutos do controle apresentaram maior atividade da PPO ao longo do armazenamento, em comparação aos frutos tratados com 1-MCP e MeSA (Figura 1B), o que pode explicar as diferenças obtidas para o índice de escurecimento. A PPO é uma das principais enzimas envolvidas com o processo de escurecimento enzimático. Quando as injúrias por frio se desenvolvem, compostos fenólicos, inicialmente contidos nos vacúolos, entram em contato com a PPO, presente no citossol, causando reações que levam ao escurecimento dos tecidos (DING et al., 1998a; MARCHART et al., 2006). Assim, possivelmente o 1MCP e o MeSA reduziram essas reações, não diretamente, mas por mecanismos de defesa ao extravazamento de solutos transmembrana, associados ao retardo da senescência.

Ao longo do armazenamento refrigerado, ocorreu o aumento da firmeza de polpa em todos os tratamentos, sendo inicialmente nos frutos do controle a partir dos 30 dias (Figura 1C). É improvável que o aumento da firmeza seja devido à perda de massa, pois as perdas não foram significativas, uma vez que os frutos estavam dentro de embalagens. Enquanto o amolecimento causado pela degradação da parede celular é um fenômeno comum na maioria dos frutos durante o amadurecimento e armazenamento, o incremento na firmeza causado pela lignificação da parede secundária tem sido observado em alguns frutos, tais como em nêspera (CAI et al., 2006a,b,c) e mangostão (Garcinia mangostana L.) submetidos a estresse por impacto (BUNSIRI et al., 2003). O aumento da firmeza de polpa de nêsperas armazenadas sob refrigeração tem sido reportado por outros autores como um sintoma de injúria por frio (DING et al., 2002a; CAI et al., 2006a), estando associado ao aumento na síntese de lignina (CAI et al., 2006a, b; YANG et al., 2008).

Os índices de podridão mantiveram-se abaixo do limite aceitável de 0,4 , estabelecido por CAI et al. (2006c), para todos os tratamentos, durante o período de armazenamento (Figura 2A). Porém, os frutos tratados com MeSa apresentaram índices de podridão mais baixos durante todo o período analisado. Isso 

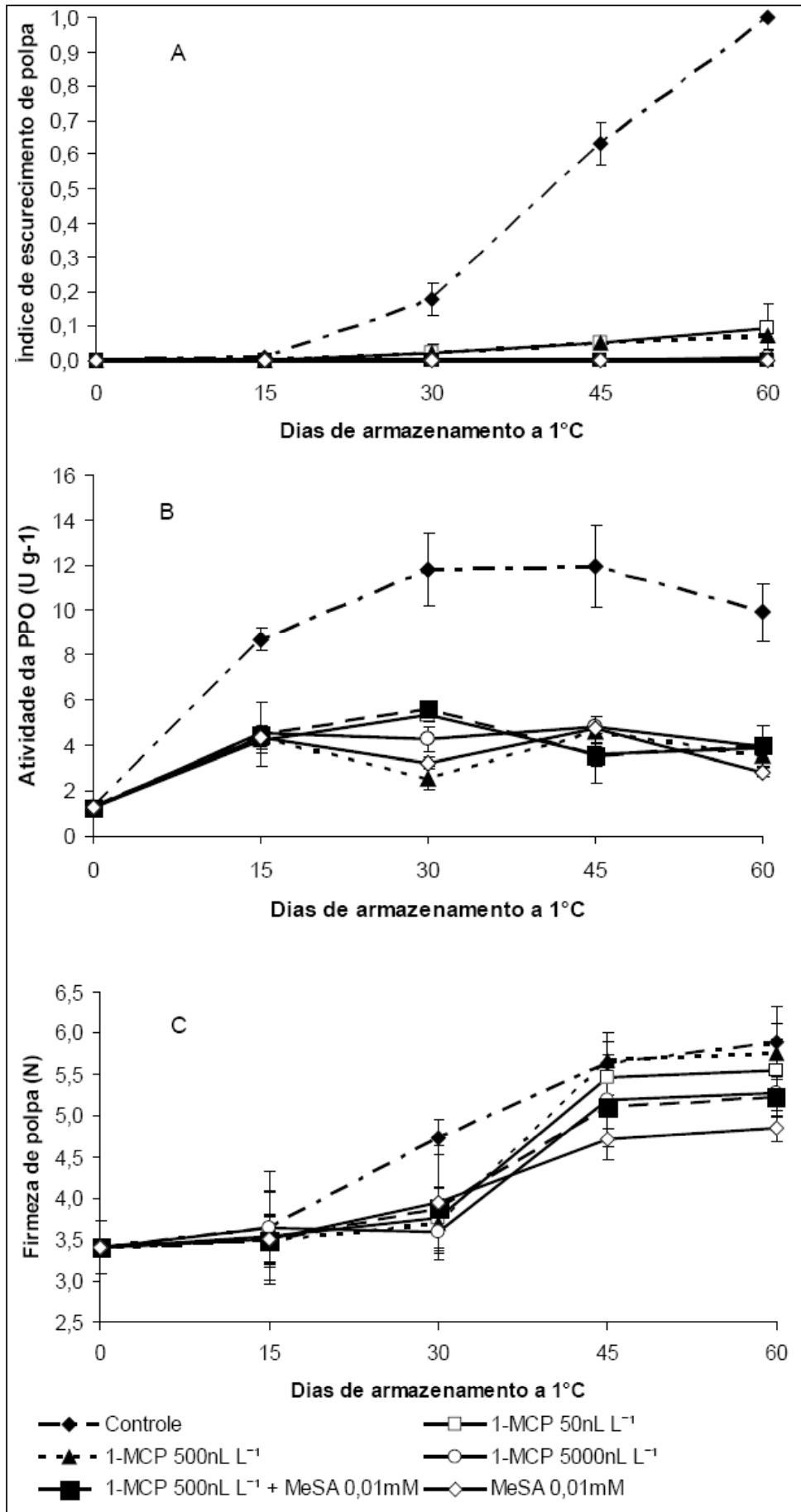

Figura 1 - Escurecimento da polpa (A); atividade de polifenoloxidase (PPO) (B); firmeza de polpa (C), em nêsperas tratadas com diferentes concentrações de 1-metilciclopropeno (1-MCP) e salicilato de metila (MeSA).

ocorreu porque os compostos salicilados são considerados sinalizadores celulares que promovem a expressão de proteínas relacionadas com a defesa de células vegetais ao ataque de patógenos (DING et al., 2002b). O Metil Salicilato é um composto orgânico utilizado principalmente em cosméticos, inclusive em produtos de higiene bucal, sendo permitido pela ANVISA(Agência Nacional de Vigilância Sanitária) na 

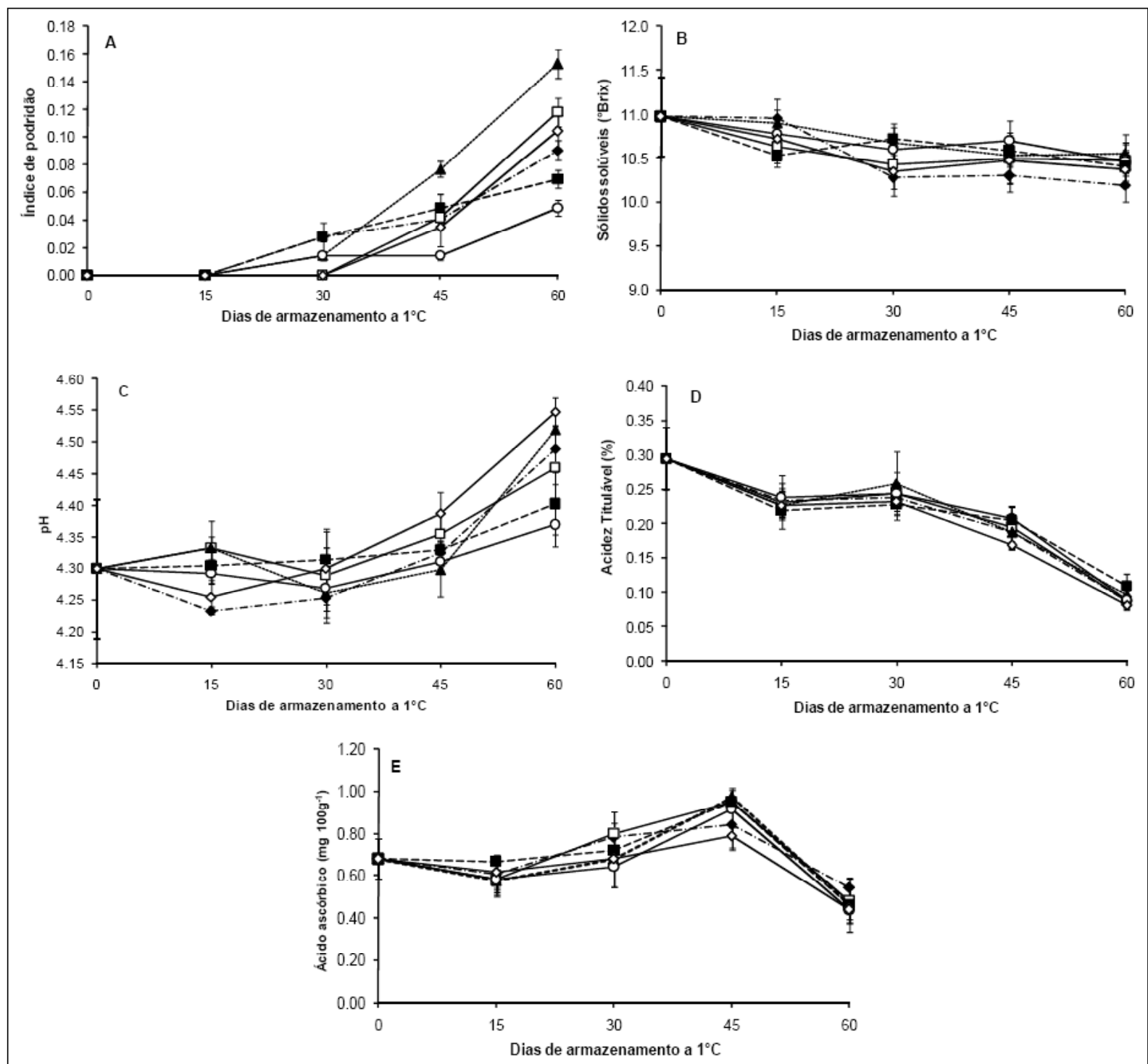

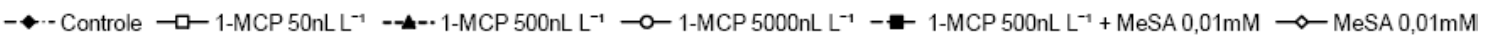

Figura 2 - Índice de podridão (A), teor de sólidos solúveis (B), pH (C), acidez titulável (D) e teor de ácido ascórbico (E) em nêsperas cv. 'Fukuhara', tratadas com diferentes concentrações de 1-metilciclopropeno (1-MCP) e salicilato de metila (MeSA).

dose máxima de $1 \%$. Em experimentos com ratas grávidas, a aplicação de $6 \mathrm{~g} \mathrm{~kg}^{-1}$ dia $^{-1}$ não mostrou sinais de teratogenicidade (ANVISA, 2005).

O teor de sólidos solúveis apresentou pequena diminuição ao longo do período de armazenamento, não havendo diferença significativa entre os tratamentos (Figura 2B). Observou-se também, em todos os tratamentos, aumento no $\mathrm{pH}$ e redução no teor de acidez titulável (Figuras 2C e 2D), o que é normal, considerando que estas variáveis estão inversamente relacionadas. A redução nos teores de SS e AT são mudanças consistentes com o amadurecimento e senescência de diversas variedades de nêspera
(ZHANG et al., 1990). Além disso, sendo a nêspera um fruto não climatérico, é esperada pouca alteração nos teores de SS nesse tipo de fruto após a colheita (ZHANG et al., 1990). A pequena diminuição nos teores de SS também pode ser atribuída à respiração dos frutos, que, embora baixa, consome parte dos carboidratos, os quais são os componentes principais dos sólidos solúveis. A diminuição da acidez pode ser devido ao consumo de ácidos na respiração, pois eles também constituem substratos respiratórios. GEBER (2001) também verificou decréscimos nos teores de acidez durante o armazenamento de nêsperas 'Mogi' armazenadas em diferentes temperaturas. 
O teor de ácido ascórbico apresentou uma elevação até 45 dias de armazenamento, mostrando decréscimo no final do armazenamento (Figura 2E). Elevações nos teores de ácido ascórbico podem ser devido à sua biossíntese, pois seus precursores podem advir da degradação da parede celular. Também pode haver redução em seus teores, em estádios avançados de senescência (AGIUS et al., 2003). O ácido ascórbico é um antioxidante natural que vai sendo consumido à medida que a senescência se desenvolve como forma de reparar danos oxidativos nas células. Esse decréscimo depende, em parte, da duração e da temperatura de armazenamento (THÉ, 2001).

\section{CONCLUSÃO}

No presente trabalho, foi verificado que o 1-MCP e o MeSa são eficientes no controle de escurecimento interno de polpa de nêsperas 'Fukuhara', sem afetar aspectos de qualidade dessa fruta. Esses tratamentos podem apresentar aplicação comercial e aumentar a conservação de nêsperas.

\section{AGRADECIMENTOS}

À Fundação de Amparo a Pesquisa do Estado de São Paulo (FAPESP), pela concessão do auxílio à pesquisa. À Rohm and Haas Química Ltda, pelo fornecimento do 1-MCP $\left(\right.$ SmartFresh $\left.{ }^{\mathrm{SM}}\right)$.

\section{REFERÊNCIAS}

ANVISA. Avaliação toxicológica do salicilato de metila. Parecer técnico n.6, Brasília, 23 ago. 2005. Disponível em: <http://portal.anvisa.gov.br/wps/portal/anvisa/home/ cosmeticos>. Online. Acesso em: 23 dez. 2010.

AGIUS, F. et al. Engineering increased vitamin C levels in plants by overexpression of a D-galacturonic acid reductase. Nature Biotechnology, v.21, p.177-181, 2003. Disponível em: <http://dx.doi.org/doi:10.1038/nbt777>. Acesso em: 16 jun. 2009. doi:10.1038/nbt777.

BLANKENSHIP, S.M.; DOLE, J.M. 1-Methylcyclopropene: a review. Postharvest Biology and Technology, v.28, p.1-25, 2003. Disponível em: <http://dx.doi.org/doi:10.1016/S09255214(02)00246-6>. Acesso em: 22 nov. 2008. doi:10.1016/ S0925-5214(02)00246-6.

BUNSIRI, A. et al. Phenolic metabolism and lignin synthesis in damaged pericarp of mangosteen fruit after impact. Postharvest Biology and Technology, v.29, p.61-71, 2003. Disponível em: <http://dx.doi.org/doi:10.1016/S0925-5214(02)00213-2>. Acesso em: 12 jun. 2009. doi:10.1016/S0925-5214(02)00213-2.

CAI, C. et al. Acetylsalicylic acid alleviates chilling injury of postharvest loquat (Eriobotrya japonica Lindl.) fruit. European Food Research and Technology, v.223, p.533-539, 2006a. Disponível em: <http://dx.doi.org/doi: 10.1007/s00217-005-02335>. Acesso em: 15 dez. 2008. doi: 10.1007/s00217-005-0233-5.
CAI, C. et al. Accumulation of lignin in relation to change in activities of lignification enzymes in loquat fruit flesh after harvest. Postharvest Biology and Technology, v.40, p.163169, 2006b. Disponível em: <http://dx.doi.org/doi:10.1016/ j.postharvbio.2005.12.009>. Acesso em: 13 jun. 2009. doi:10.1016/j.postharvbio.2005.12.009.

CAI, C. et al. Effect of 1-MCP on postharvest quality of loquat fruit. Postharvest Biology and Technology, v.40, p.155162, 2006c. Disponível em: <http://dx.doi.org/doi:10.1016/ j.postharvbio.2005.12.014>. Acesso em: 13 jun. 2009. doi:10.1016/j.postharvbio.2005.12.014.

CAMPOS, J.T. et al. Qualidade pós-colheita de nêsperas submetidas ao armazenamento sob baixa temperatura e atmosfera modificada. Ciência e Tecnologia de Alimentos, v.27, n.2, p.401-407, 2007. Disponível em: <http://www.scielo.br/ doi:10.1590/S0101-20612007000200033>. Acesso em: $23 \mathrm{dez}$. 2010. doi:10.1590/S0101-20612007000200033.

DING, C. K. et al. Purification and properties of polyphenol oxidase from loquat fruit. Journal of Agriculture and Food Chemistry, v.46, p.4144-4149, 1998a. Disponível em: <http:/ /dx.doi.org/doi:10.1021/jf980093s $>$. Acesso em: 10 maio, 2008. doi: $10.1021 / \mathrm{jf} 980093 \mathrm{~s}$.

DING, C. K. et al. Effects of storage temperatures on physiology and quality of loquat fruit. Postharvest Biology and Technology, v.14, p.309-315, 1998b. Disponível em: <http:/ /dx.doi.org/doi:10.1016/S0925-5214(98)00053-2>. Acesso em: 9 mar. 2009. doi:10.1016/S0925-5214(98)00053-2.

DING, C. K. et al. Modified atmosphere packaging maintains postharvest quality of loquat fruit. Postharvest Biology and Technology, v.24, p.341-348, 2002a. Disponível em: <http:/ /dx.doi.org/doi:10.1016/S0925-5214(01)00148-X>. Acesso em: 9 mar. 2009. doi:10.1016/S0925-5214(01)00148-X.

DING, C.K. et al. Jasmonate and salicylate induce the expression of pathogenesis-related-protein genes and increase resistance to chilling injury in tomato fruit. Planta, v.214, p.895-901, 2002b. Disponível em: <http://dx.doi.org/doi: 10.1007/s00425001-0698-9>. Acesso em: 9 mar. 2009. doi: 10.1007/s00425001-0698-9.

GEBER, D.A.O. Uso de atmosfera modificada no prolongamento da vida pós-colheita de nêsperas cv. Mogi, 2001. 66f. Dissertação (Mestrado em Ciências dos Alimentos) - Universidade Federal de Lavras, MG.

MARCHART, S.S. et al. Isolation of a latent polyphenol oxidase from loquat fruit (Eriobotrya japonica Lindl.): kinetic characterization and comparison with the active form. Archives of Biochemistry and Biophysics, v.446, p.175185, 2006. Disponível em: <http://dx.doi.org/doi:10.1016/ j.abb.2005.12.004>. Acesso em: 10 maio, 2008. doi:10.1016/ j.abb.2005.12.004.

SALA, J.M. Involvement of oxidative stress in chilling injury in cold-stored mandarin fruits. Postharvest Biology and Technology, v.13, p.255-261, 1998. Disponível em: <http:// dx.doi.org/doi:10.1016/S0925-5214(98)00011-8>. Acesso em: 9 mar. 2009. doi:10.1016/S0925-5214(98)00011-8.

SHAN, L.L. et al. Characterization of cDNAs associated with lignification and their expression profiles in loquat fruit with 
different lignin accumulation. Planta, v.227, p.1243-1254, 2008. Disponível em: <http://dx.doi.org/doi:10.1007/s00425008-0696-2>. Acesso em: 9 mar. 2009. doi: 10.1007/s00425008-0696-2.

THÉ, P.M.P. Efeitos da associação de tratamento hidrotérmico, cloreto de cálcio e atmosfera modificada sobre o escurecimento interno e qualidade do abacaxi 'Smooth Cayenne'. 2001. 128f. Tese (Doutorado em Ciência dos Alimentos) - Universidade Federal de Lavras, MG.

VANALTVORST, A.C.; BOVY, A.G. The role ethylene in the senescence of carnation flowers, a review. Plant Growth Regulation, v.16, p.43-53, 1995. Disponível em: <http:// dx.doi.org/doi:10.1007/BF00040506>. Acesso em: 13 jun. 2009. doi: 10.1007/BF00040506.

VAN LOON, L.C.; ANTONIW, J.F. Comparison of the effects of salicylic acid and ethephon with virus-induced hypersensitivity and acquired resistance in tobacco. European Journal of Plant Pathology, v.88, p.237-256, 1982. Disponível em: <http://dx.doi.org/doi: 10.1007/BF02000130>. Acesso em: 11 dez. 2008. doi:10.1007/BF02000130.
XU, X.; TIAN, S. Salicylic acid alleviated pathogen-induced oxidative stress in harvested sweet cherry fruit. Postharvest Biology and Technology, v.49, p.379-385, 2008. Disponível em: 〈http://dx.doi.org/doi:10.1016/j.postharvbio.2008.02.003>. Acesso em: 11 dez. 2008. doi:10.1016/j.postharvbio.2008.02.003.

YANG, S. et al. Expression of expansin genes during postharvest lignification and softening of 'Luoyangqing' and 'Baisha' loquat fruit under different storage conditions. Postharvest Biology and Technology, v.49, p.43-53, 2008. Disponível em: <http:/ /dx.doi.org/doi:10.1016/j.postharvbio.2008.01.005>. Acesso em: 9 mar. 2009. doi:10.1016/j.postharvbio.2008.01.005.

ZHANG, Y. et al. The role of salicylic acid in postharvest ripening of kiwifruit. Postharvest Biology and Technology, v.28, p.6774, 2003. Disponível em: <http://dx.doi.org/doi:10.1016/S09255214(02)00172-2>. Acesso em: $11 \mathrm{dez}$. 2008. doi:10.1016/ S0925-5214(02)00172-2.

ZHANG, H.Z. et al. The germoplasm resources of the genus Eriobotrya with special reference on the origin of E. japonica Lindl. Acta Horticulturae Sinica, v.17, p.5-12, 1990. 